\title{
Developing Information System Strategic Planning for Smarter Regional Development in Ternate Smart Island
}

\author{
Minhajuddin Kasman AR ${ }^{1, *}$ Farisya Setiadi ${ }^{1}$
}

\author{
${ }^{1}$ Faculty of Computer Science University of Indonesia Depok, Indonesia \\ *Corresponding author. Email: minhajuddin.kasman@ui.ac.id
}

\begin{abstract}
Regional development is a foundation of successful national development. In order achieve better regional development process, Ternate has been preparing their capability for smart city transformation with the title of Ternate Smart Island. However, the challenges faced by the government regarding ICT implementation and planning is tough to overcome due to the lack of strategy and capable human resources. That said, this research is conducted to identify strategic application portfolio based on Ward and Peppard's Strategic Model. Therefore, it can support regional development by Communication, Informatics, and Encrypting Services (DISKOMSANDI) which is directly involved to ICT management in Ternate. This research utilizes Value Chain, combination of SWOT and Porter's Diamond Model, and PEST to find out current condition along with McFarland Grid to map current and strategic applications. By the end of the research, a strategic application portfolio for smarter regional development in island territories which has a purpose of harmonizing and optimizing resources in order to deliver more effective and efficient services and regional development itself will be introduced.
\end{abstract}

Keywords - Strategic IS Planning, Smart Island, Regional, Development, SWOT Analysis, McFarland Strategic Grid.

\section{INTRODUCTION}

The body text starts with a standard first-level Regional development is a foundation of national development. These days the regional development is often linked to smart city approach. Through Presidential Regulation No. 95 of 2018 regarding electronic-based government system (SPBE), Indonesia attempt to improve the quality of governance by involving smart approach in hopes to generate more effective, clean transparent, and reliable government system. Apart of information, communication, and technology (ICT) involvement, a city is considered smart if the government can invest in human resources, social, digital infrastructure, etc. to stabilize economic growth and the quality of life for the ones who live in it. This can be achieved through participative governance [1] not only appointed to government but also to the people of a city since they also have critical roles in successful smart city concept.

In the complex competition, the role of information technology in an organization has become significant. IT is no longer considered luxurious where only accessible by certain parties. In the contrary, IT is a must-have component for organizations if they are to compete in current dynamic and volatile environment. The use of IT in organizations is provenly capable to support strategic activities. Therefore, it has the opportunity to become an enabler which can provide smarter solutions to deliver values of organizations in various sector including government. The advances of technology in government sector allow the instances to bring out the best services to citizen. By making use of IT, it is possible to the instances to transform the system into the more transparent, effective, and efficient. 
According to head of Communication, Informatics, and Encryption (DISKOMSANDI), one of the keys towards successful regional development in Ternate is to optimize IS/IT involvement in order to support the transformation into Ternate Smart Island which is also stated in the organization strategic planning document [2]. Nonetheless, the expectations of service deliverance performance by numbers of regional units has not been met. There had been inconsistent opinions among regional units regarding which unit is responsible to manage Ternate Smart Island. This inconsistent condition leads to poor management and integration between units whereas data and information among them is highly needed in order to provide better insights to deliver smarter services [3]. That said, the IS/IT strategic plan is required by Ternate Government as a reference to perform their duties in bringing Ternate Smart Island to the right track.

\section{MATERIALS AND METHODS}

\subsection{Regional Development}

Regional development is a pillar of national development. In order to operate successful regional development, there are development aspects which need to be established namely growth; equalization; up to regional continuity based on location, space, and social economy [4]. In regional development, there is a concept which is focused in developing cities called urban development. This concept can only be adopted if a region has the capability to do so. That said, rural regions will find it difficult to adopt the concept.

A region is considered a city if it has high population, social levels, and heterogeneous and materialistic economy [5]. That said, smarter approach needs to be taken in order to develop the region. In this era, one of the smart approaches which can be adopted for the respective task is by applying ICT in the development.

\subsection{Smart Island}

Smart island adopts the concept of smart city. The main differentiation between the two concepts is smart island aims to be implemented in island-based regions. Some additional purposes of this concept which differentiate itself with smart city is to make the best use of islands' resources and mitigate issues which come with climate change. The massive climate change around the world demands these regions to take anticipative actions because they are the first ones to receive the impact. However, the limitation regarding accessibility from one island to another makes it difficult and costs more to accommodate the needs. That said, island planning is as important as city planning for a region so that they can bring out the best version of the island in terms of smart development and value deliverance to each beneficiary [6].

\subsection{Data Collection}

In this research, collected data is grouped into two different category namely primary and secondary data. Primary data is collected by interviewing the actors who are involved in the development of Ternate Smart Island and have major roles in its implementation including Head of Ternate Agency of Regional Development Planning (BAPPEDA) and Head of Information Technology unit of DISKOMSANDI. Furthermore, Secondary data will be gathered by studying the documentation such as DISKOMSANDI strategic planning and Ternate annual government reports.

\subsection{Strategic IS/IT Planning Methodology}

There are options of framework that can be used to plan IS/IT strategy. One of the most popular frameworks with tons of success stories is Ward and Peppards's. This framework offers an approach to generate strategic planning of IS/IT in organizations which is produced by considering the organizations' strategy and drivers for change. There are steps to formulate IS/IT strategy. As shown in Fig. 3, impact of potential IS/IT for the industry needs to be identified initially before evaluating which IS/IT is needed to deliver organizations' value. Furthermore, best way to implement the needed IS/IT needs to be determined before mapping the strategy for execution. IS/IT strategy formulation includes set of process such as inputs, outputs, and other activities. The processes are [7]:

- Inputs: the information gathering process regarding environments of internal business, external business, internal IS/IT, and external IS/IT. Furthermore, the information will then be used to discover critical issues which affects organization's performance. This internal business might be discovered by analysing organization's business strategy, processes, and resources. Meanwhile, external environment is gathered by figuring out organizations market positions and factors which might impact the business. It is also a good idea to examine facts regarding organization's competitor to achieve opportunities and threats. Furthermore, identification of current IS/IT for both internal and external environment is needed to identify perspective of respective environment in business, application portfolio, etc.

- Outputs: the deliverables which are produced by analysing inputs. There will be three points which can be considered as outputs in IS/IT strategic planning including IS/IT strategy management, business IS strategies, and IT strategy

Ward and Peppard's methodology provided set of stages that can be adopted by organizations to develop IS/IT strategies. Along with the stage, they also provided methods regarding how to process it by using several 
tools. However, modifications need to be performed in this study in order to align the strategy to the management of Ternate Smart Island. The Figure 1 depict the default model of stages that's provided in Ward and Peppard's methodology.

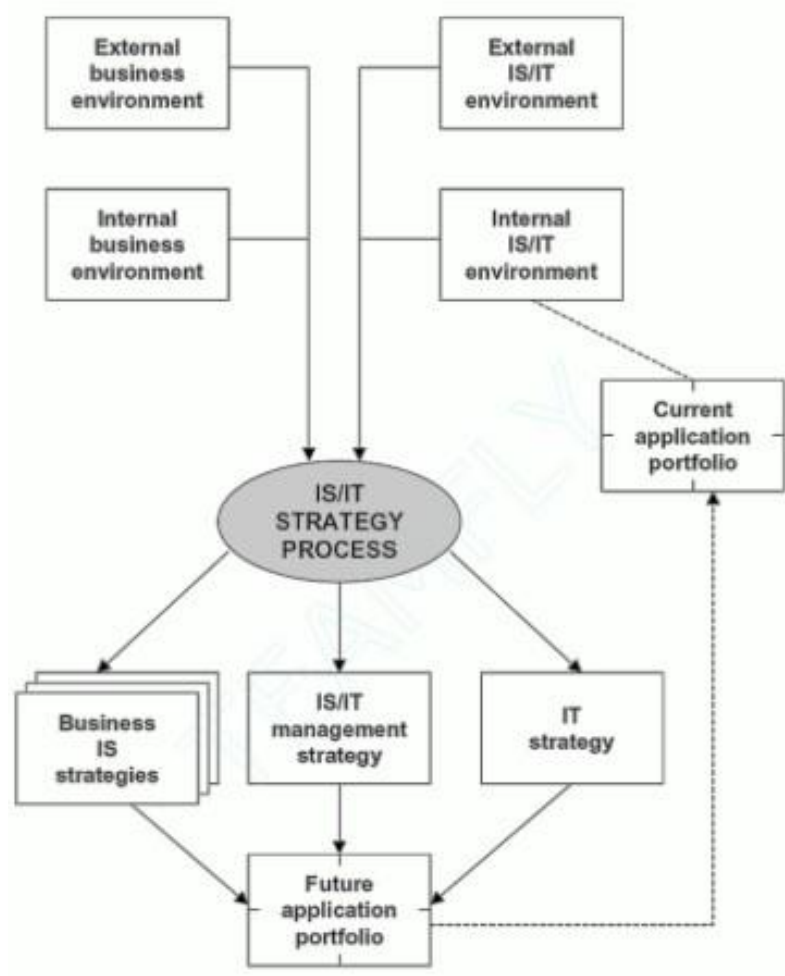

Figure 1 Ward and Peppard's IS/IT Strategic Model [5]

In identifying both internal and external environments, this study utilized Mission Model Canvas (MMC) to identify business model for mission-driven organization [8]; value chain; PEST; and Strengths, Weaknesses, Opportunities, and Threats (SWOT) analysis. However, because of the case study that is related to government, this study proposed to combine the SWOT technique with Porter's Diamond Model (PDM which can be utilized to support the identification of a region's competitive advantages [9]. This combination was done so that each section of SWOT could be identified in multiple perspective that is relevant to regional development. On the other hand, trend analysis was conducted to support the identification of external IS/IT condition.

Finally, once the previous stages were finished, this study argued to find out IS/IT needs so that the future condition regarding optimized internal organization environment and future application portfolio can be formulated.

\section{RESULTS}

\subsection{Organization's Mission Model}

To identify internal business environment, analysis is conducted by mapping the environment into mission model canvas which contains some aspects that is related to service deliverance in DISKOMSANDI from mission offerings up to measurement of mission achievement. Additionally, to support the facts which were obtained during the modelling of MMC, this study also proposed to analyse the organization's value chain to determine primary and secondary activities that was being done in the organization.

Results of modelling the MMC of DISKOMSANDI shows that the mission offerings given by the regional unit is to develop and realize regional policies regarding communication, informatics, and encryption. The beneficiaries who receive benefits of the mission are citizens and other regional units of Ternate. However, both citizens and regional units also has their roles as DISKOMSANDI's key partners along with provincial government. The media utilized by DISKOMSANDI to deliver their mission varies from regional official website to billboard ads. Furthermore, to get buy-ins from the beneficiaries, DISKOMSANDI provided internet in public spots. DISKOMSANDI also served and provided for citizens and other regional units in response to their IT needs as another approach to get the buy-ins.

In realizing the mission, there were several activities that needed to be performed namely formulating and planning regional policies; performing operational tasks; and technical service of administration. Furthermore, to support the activities, there are aspects which required expenses. These aspects are mapped inside cost structure of the mission model. Finally, to make sure that mission is accomplished, there were some indicators that needed attention. These indicators include number of public services which can be accessed online, number of available regional databases which are secure and accurate, areas which are covered by public service, and percentage of regional units which support open information for public.

\subsection{Value Chain Analysis}

To strengthen the result of analysis regarding internal business environment, value chain tools was also being utilized. Not only to support the previous statements, the purpose of this utilization is also to map the activities that are being done in DISKOMSANDI into two different category namely primary and secondary activities which differentiate the activities that are mandatory to achieve the unit's goals and the ones that are considered as support. Figure 2 depicts the value chain of DISKOMSANDI. 


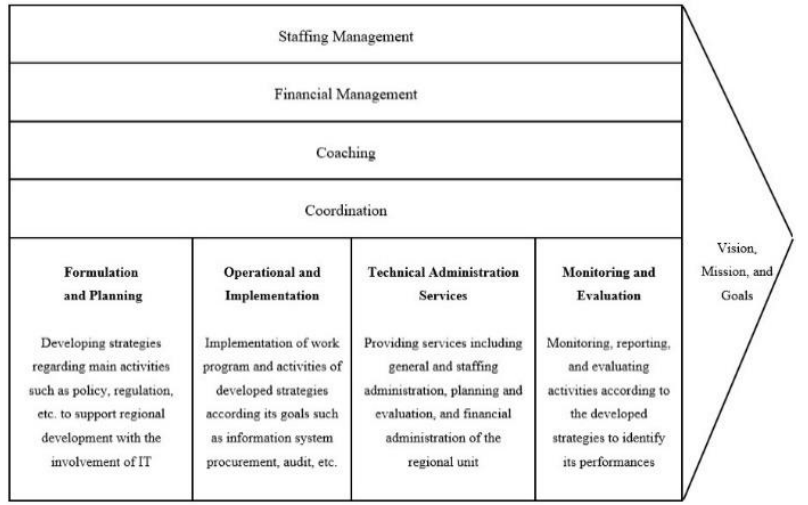

Figure 2 Value Chain of DISKOMSANDI

As seen in Figure 2, the horizontal block depicts secondary activities which are being done to support the vision, mission, and goals of DISKOMSANDI. These blocks include staffing management where human resources are being managed, financial management, coaching to provide trainings regarding IT whether to internal nor external parties, and coordination to ensure integration and effective collaboration. On the other hand, the vertical blocks which include formulation and planning, operational and implementation, technical administration services, and monitoring and evaluation are the primary activities which need to be performed in order to achieve the regional unit's vision, mission, and goals.

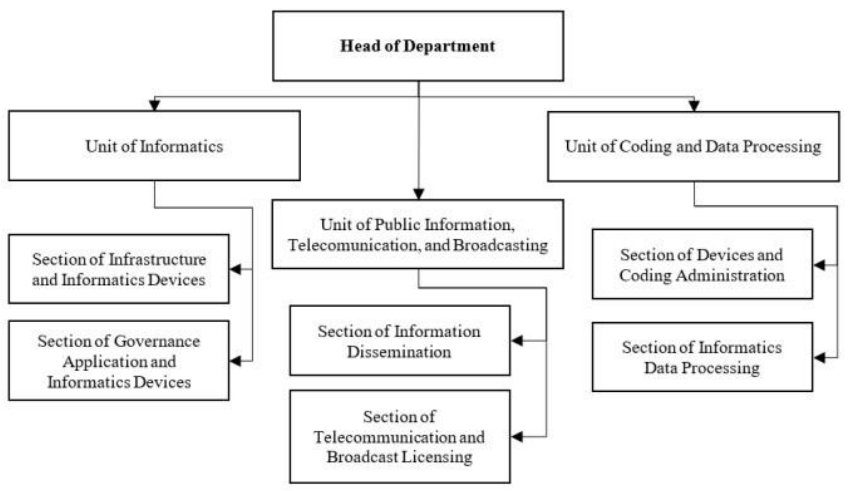

Figure 3 IS/IT Organization of DISKOMSANDI

\subsection{Internal IS/IT Environment}

Generally, DISKOMSANDI is an organization which handle various kind of IT implementation to support regional development of Ternate. The activities vary from planning up to procurement. Figure 3 show the IS/IT organization of the regional unit.

DISKOMSANDI stated that there was minimal involvement of information systems. One of the systems which are utilized by the regional unit is E-Procurement. This system is considered as support system knowing that even without this system, the activities can be done manually.
When it comes to Ternate Smart Island, DISKOMSANDI initiated application portfolio by introducing an application namely SI APIK which is a public services complaint system. By making use of this system, citizens can submit complaints regarding unsatisfied public services. The services include waste, traffic issues, clean water, damaged infrastructure, accident, natural disaster, and social issues. The complaints can be filed by providing evidence in the form of pictures as an assurance of originality regarding the complaints.

\subsection{SWOT Analysis}

The data in this analysis was gathered from strategic plan of DISKOMSANDI and annual reports of Ternate. This analysis is combined with Porter's Diamond Model to identify aspects that is related to regional development.

\subsubsection{Strength}

a) Factor Conditions:

1) Human resources such as civil apparatus, staff, etc. in regional units of Ternate are considered adequate knowing that there are variety in group composition, ranks, eselonialization in various positions, educational background, etc. Therefore, optimization of service deliverance to beneficiaries can be achieved.

2) Ternate has built interconnected network infrastructure across its islands especially in the mind island. This allows the citizens to make use of internet in terms of receiving public services. This is beneficent to DISKOMSANDI and other regional units in the development of Ternate Smart Island.

\section{b) Demand Conditions:}

In recent years, Ternate has received services and products which are generated by local organizations. There are parties from various higher education institutions, communities, freelancers, etc. which take parts in delivering these services and products.

\section{c) Related and Support Industries:}

Ternate in past few years has multiple industries which can facilitate the development of IT. These industries include higher education institutions which produced individuals with IT background, communities and non- formal organizations such as Zona IT and other IT bootcamps which can promote the technical skills and other IT practices of their members. This opens the room of collaboration between industries and regional units to innovate.

\section{d) Firm Strategy, Structure and Rivalry:}

District heads with capability, acceptability, mobility, and many activities allows the region to grow faster. This 
also gives the region ability to partner up with alliances from various government sectors such as judiciary and legislative parties; mass organizations; and nongovernment organizations (NGO).

\subsubsection{Weakness}

\section{a) Factor Conditions}

Even though the regional unit has capable human resources. The image is weak due to the lack of professionality in terms of services. This statement is supported by administration system which is not well structured and standard operating procedure (SOP) which is yet to be developed.

\section{b) Related and Support Industries}

One of the most supportive industries in providing resources to technological advancement in Ternate is higher education institutions. However, some of the institutions are not well accredited.

\section{c) Firm Strategy, Structure and Rivalry}

One of the impactful weaknesses of regional units in Ternate is the lack of efficiency regarding financial management. This weakness is occurred due to missarranged financing, budgeting, accounting, and inspection systems. This tarnishes the image of regional units and generates negative opinions of citizens about the transparency of public money management.

\subsubsection{Opportunities}

\section{a) Factor Conditions}

1) Attractiveness of numerous tourism sites in Ternate such as beaches, historical spots from Portuguese forts, etc. Some events which attended by both national and international tourists are total solar eclipse in 2017 and other cultural festivals that's recorded in MURI records. Regional units like DISKOMSANDI can make use of this factor by involving IT to enrich ways to interact, learn, and get values of it.

2) The facts that Ternate is centre of excellence in Maluku Utara generated interests to comers. Education institutions, health facilities, etc. Ternate are well known across Maluku Utara even nationally.

\section{b) Demand Conditions}

Technological advancement generates opportunities which can be beneficent to Ternate. The facts that many citizens in Ternate are now well-aware of this advancement making it possible for DISKOMSANDI as a regional unit which is responsible to this matter to innovate based on the trends.

\section{c) Firm and Support Industries:}

There is enough delegation of authority to regional government. One of it is stated on Government Regulations No. 38 of 2007 about the allocation of governance activities among Central Government, Provincial Government, and District Government which opened opportunities for the development of potential regions in terms of its vision realization. Furthermore, the regional autonomy also generated the opportunity for a region to improve and optimize their public services according to its characteristics and needs.

\subsubsection{Threats}

\section{a) Factor Conditions}

Massive population growth in Ternate leads to massive growth in the aspects of economy, social, politics, culture, and so on. In 2011, 187.322.957 people lived in Ternate until the number is increased by 218.017 in 2016 making the population growth rate of the region is $2.3 \%$. This factor is considered a threat knowing that the massive population might cause social issues. By the end of 2019, the number of unemployed people in Ternate nearly touched $6 \%$ which is around 5000 in total.

\section{b) Demand Conditions}

Increased awareness among citizens regarding democratic activities leads to personal interest prioritization. This has the possibility of generates ignorance among citizens and threaten the stability of politics and economy. Therefore, the conducive investment of the region can be impacted.

\section{c) Related and Support Industries}

Decreasing of commerce intensity and weak service providers sector threatened the stability of economic growth in Ternate knowing that both aspects are the ones that hold joints of the region's economy.

\subsection{PEST Analysis}

To strengthen the argument of identified external environment, PEST analysis was doe and the results are as follows:

\section{a) Political}

DISKOMSANDI is a regional unit which operates under Ternate Government. This demands the unit to follow regulation from central and provincial government. To increase citizens trust to their performance, regional units need to support information disclosure as stated in Governmental Regulation No. 61 of 2010 about Implementation of Constitution No. 14 of 2018 about Public Information Disclosure. Furthermore, there are other regulations with purpose of improving public services namely Presidential Regulation No. 95 of 2018 about Electronic-based Government System 
(SPBE), Presidential Regulation No. 81 of 2010 about Grand Design of 2010- 2025 Bureaucracy Reformation, etc. as well as government initiative to realize 100 Smart Cities in Indonesia.

\section{b) Economy}

Financial of regional development is mainly regulated by Ministry of Finance Regulation. Due to global pandemic in 2020, The Ministry issued regulation in Ministry of Finance Regulation No.38 of 2020 about National Financial Policy for Mitigation of COVID19 and/or Threats Which Endanger National Economy and/or Financial System Stability. Other aspect which impacts the economy and its performance might come from high and unstable dollar exchange rate which affects the price of IT devices.

\section{c) Social}

Global pandemic that is occurred in 2020 affected social activities of people in various sector of industries. According to research conducted by Inventure [10] there are 4 mega shifts which were generated during COVID19 pandemic those are stay @ home lifestyle, emphatic society, go virtual, and bottom of the pyramid. In terms of technology, these shifts push business actors to perform their activity remotely. It even initiated digital transformation to some organizations. This condition limited the possibility of direct social interaction among people. Instead, social interaction and other organization activities can be done remotely. That said, DISKOMSANDI and other regional units of Ternate need to adjust their activities in order to face the condition without losing their values in delivering services.

\section{d) Technology}

The massive use of internet these days allows organizations from various sector to take benefit out of it. Technology is no longer a luxurious thing which can only be possessed by certain parties. These days technology has become a must- have aspect for organizations if they are to compete in volatile and dynamic business environment. By involving technology to their activities, organizations might acquire competitive advantage. In government sector, according to Gartner [11], there are numbers of technology trends which are potential to optimize or transform public services. These trends include citizen digital identity, anything as a service (XaaS), shared services 2.0, augmented intelligence, etc

\subsection{Future Applications}

Table 1 contains future applications of DISKOMSANDI along based on information needs. To identify the roles, the applications are mapped into McFarland strategic grid as shown in the following Table 2.
As shown on the table, there are four different quadrants which contain information systems according to its roles. Information systems on which regional units depend to perform their daily activity are included in key operational quadrant. Support quadrant include optional systems which support public services. However, even if these systems are not utilized, public services can still be delivered. High potential systems are the ones which are unproven yet possible to impact public services in a good way. Finally, strategic quadrant contains systems which can create competitive advantage. Nonetheless, the implementation of these strategic information systems requires both minor and major changes inside regional units. These changes depend on how impactful the systems to their activities.

Table 1. Future Applications

\begin{tabular}{|c|c|c|}
\hline No & IS Needs & IS \\
\hline 1 & Public data disclosure & TSI Data \\
\hline 2 & SIMRAL integration & E-Procurement \\
\hline 3 & IS for education & Smart Edu \\
\hline 4 & IS for Ternate culture & E-Culture \\
\hline 5 & IS for tourism in Ternate & TSI Visitour \\
\hline 6 & IS for knowledge management & SI Mapan \\
\hline 7 & IS for speedboat transportation & Smart Boat \\
\hline 8 & $\begin{array}{l}\text { IS for water-based } \\
\text { transportation port }\end{array}$ & Smart Port \\
\hline 9 & IS for public transportation & TSI Mobility \\
\hline 10 & $\begin{array}{l}\text { IS for human resource } \\
\text { management }\end{array}$ & HR System \\
\hline 11 & $\begin{array}{l}\text { Content and functional } \\
\text { upgrade }\end{array}$ & Website \\
\hline 12 & IS for partnership management & TSI Alliance \\
\hline 13 & IS for public library & TSI E-Lib \\
\hline 14 & $\begin{array}{l}\text { IS for environment } \\
\text { management } \\
\text { (disaster mitigation, security, } \\
\text { etc.) }\end{array}$ & Smart Env \\
\hline 15 & Integration with E-Procurement & SIMRAL \\
\hline 16 & IS for asset management & TSI Assets \\
\hline 17 & IS for financial management & Financial MS \\
\hline
\end{tabular}

The implementation of information systems in support quadrant does not have to be done costfully. This implementation can be efficient by involving vendors knowing that the systems are only support and does not have critical part in regional units' primary activities. In the development of Smart Edu, data regarding educational institutions along with its curriculum in 
Ternate need to be considered as inputs. However, best practices should also be provided so that the institutions can have the opportunity to improve their system. Same goes to TSI Mobility, TSI E-Lib and TSI Assets. On the other hand, Website of Ternate government can be improved by providing real-time data to support public data disclosure by integrating it with TSI Data from strategic quadrant. Furthermore, High potential information systems might require attention knowing that its existence might affect organization's performance. For example, E-Culture and TSI Visitour implementation. This implementation demands regional unit to create and maintain relationships with local sites managers in hope that these relationships can develop synergy towards better information delivery regarding culture and tourism sites in Ternate.

Table 2. Future Application Portofolio

\begin{tabular}{|c|c|}
\hline Strategi & High Potential \\
\hline TSI Data SI & TSI Visitour \\
Mapan TSI & E-Culture \\
Alliance & Smart Boat \\
Smart Env & Smart Port \\
\hline E-Procurement & Smart Edu \\
SIMRAL & TSI Mobility \\
HR System & Website \\
Financial MS & TSI E-Lib \\
& TSI Assets \\
\hline Key Operational & Support \\
\hline
\end{tabular}

\section{DISCUSSION}

According to Presidential Regulation, it is necessary for regional units to make use of SPBE for better, more effective, and efficient public service deliverance. However, in order to bring out the best potential of the systems, it is required that civil apparatus or staff can show their professionality and ensure their capability to make use of the systems. The effective utilization of information systems not only rely on the users but also the functionality whether the systems can complete needs of an organization or not.

Findings in this study indicate that in order to better the regional development of, it is required to firstly understand the characteristics and condition of a region. Not only that, it is also necessary to identify external condition from various perspectives. This is done so that we can provide relevant recommendation regarding strategic information planning which can fulfil the needs of the organization. As a regional unit which support city government, identification of both internal and external condition needs to be performed by considering the perspective of regional competitive advantage which is the reason why this research proposed to combine Porter's Diamond Model with SWOT analysis. Furthermore, IS needs can be identified from information needs based on internal and external condition.

Apart from the systems shown in McFarland Strategic Grid, there are various software which can be implemented by regional units in Ternate. For instance, when it comes to teamwork and project management regional units can take advantage by utilizing tools such as Jira, Microsoft Project, etc. Another example which some of it is already utilized is Microsoft Office packaged software. This software includes numbers of tools to support civil apparatus and staff productivity in providing quality services. Furthermore, there are also tools of which the regional units can take advantage when condition which demand their activities to be done remotely occurred such us COVID-19 global pandemic in 2020. This condition lead many actors in the various sector of industries including government to work from home and study from home. To ensure the activities to achieve their goal keep going, regional units can maximize their remote activities such as online meetings, coordination, etc. by using tools like Microsoft Teams, Google Hangout Meet, Zoom, etc

\section{CONCLUSION}

In order to transform a city into smart city, there are aspects which need serious can careful consideration. It is not only about implementing smart and powerful technologies but also making sure that people can get the values from it. Ternate has initiated the transition to become Smart Island started by accommodating internet access to numbers of public areas. This approach opens opportunities to provide integrated information systems which can bring positive impact to Ternate Smart Island program. These systems can be identified by using Peppard \& Ward strategic model and understanding the regional condition of the city.

One of the limitations in this study is that it does not fully cover IS/IT strategy. It is commonly known that fulfilling IS/IT needs can not only be done by procuring information systems but also other aspects such as governance, policy, data management, etc. However, this study opens the opportunity for other researcher to enrich the topics regarding island-based regions development plan with the involvement of IS/IT.

For future research which study similar topics, it is preferred that validation of data can be performed knowing that business environments these days are volatile as well as the technological advancement which introduce new solutions every short period of time. 


\section{REFERENCES}

[1] Caragliu, C.D. Bo, P. Nijkamp, Smart City in Europe, Journal of Urban Technology, 2011.

[2] DISKOMSANDI, Strategic Planning of DISKOMSANDI 2016-2020, Ternate, 2016.

[3] DISKOMSANDI, Analysis and Evaluation of ICT Implementation in Ternate, Ternate, 2019.

[4] A. Anwar, Ketimpangan Pembangunan Wilayah dan Pedesaan: Tinjauan Kritis, Bogor: P4Wpress, 2005.

[5] Bintarto, Interaksi Desa - Kota dan Permasalahannya, Jakarta: Ghalia Indonesia, 1989.

[6] Smart Island Initiative, New Pathways of European Islands to Create Smart, Inclusive, and Thriving Island Societies for an Innovative and Sustainable Europe, Smart Island Initiative, 2020.

[7] J. Ward, J. Peppard, The Strategic Management of Information Systems: Building A Digital Strategy 4th Edition, West Sussex: John Wiley \& Sons, 2016.

[8] Strategyzer, S. Blank, The Mission Model Canvas: An Adapted Business Model Canvas For Mission- Driven Organizations, Strategyzer, 5 February 2016. [Online]. Available: http://www.strategyzer.com. [Accessed 28 March 2020].

[9] M. Naserbakht, E. Asgharizadeh, A. Mohaghar, J. Naserbakht, Merging the Porter's Diamond Model with SWOT Method in Order to Analyze the Iranian Technology Parks Competitiveness Level, in PICMET 2008, Cape Town, 2008.

[10] Y.F. Fatahillah, A. Rachmaniar, I. Hanifah, Consumer Behavior New Normal After COVID19: The 30 Prediction, Inventure Knowledge, 2020.

[11]Gartner, Top 10 Government Technology Trends for 2019-2020, Gartner, Australia, 2019. 